Check for updates

Cite this: RSC Adv., 2017, 7, 54142

Received 19th October 2017

Accepted 20th November 2017

DOI: 10.1039/c7ra11548b

rsc.li/rsc-advances

\section{Poly(acrylonitrile-co-2-methylenesuccinamic acid) as a potential carbon fiber precursor: preparation and stabilization}

\author{
Huifang Chen, ${ }^{a}$ Yuexiu Pan, ${ }^{a}$ Shengfei Hou, ${ }^{a}$ Zhilin Shao, ${ }^{a}$ Yuqing Hong ${ }^{a}$ \\ and Anqi Ju (D) *ab
}

A novel bifunctional comonomer 2-methylenesuccinamic acid (MLA) was synthesized to prepare poly(acrylonitrile-co-2-methylenesuccinamic acid) [P(AN-co-MLA)] copolymers, which can improve the stabilization of polyacrylonitrile significantly as a carbon fiber precursor. The structure and stabilization of P(AN-CO-MLA) copolymers with different monomer feed ratios of AN/MLA were characterized by elemental analysis (EA), Fourier transform infrared spectroscopy (FTIR), X-ray diffraction (XRD) and differential scanning calorimetry (DSC). Reactivity ratio studies shows that MLA possesses higher reactivity than AN, resulting in higher MLA content in P(AN-CO-MLA) copolymers than in the feed. The molecular weight and conversion of copolymer decrease gradually with the increase of MLA content in the feed. Comparing with PAN homopolymer, P(AN-CO-MLA) copolymer has two or even three exothermic peaks, and the initial temperature of $\mathrm{P}(\mathrm{AN}-\mathrm{CO}-\mathrm{MLA})$ copolymer is $\mathrm{ca} .70{ }^{\circ} \mathrm{C}$ lower than that of PAN, which broadens the exothermic peak. The $\Delta H / \Delta T$ reduces from $34.01 \mathrm{~J} \mathrm{~g}^{-1}{ }^{\circ} \mathrm{C}^{-1}$ to less than $17.67 \mathrm{~J} \mathrm{~g}^{-1}{ }^{\circ} \mathrm{C}^{-1}$, confirming that the incorporation of MLA can avoid centralized heat release effectively. In addition, the extent of stabilization increases as the MLA content in P(AN-CO-MLA) copolymer increases under the same heat treatment conditions. The activation energy $\left(E_{\mathrm{a}}\right)$ calculation shows cyclization $E_{\mathrm{a}}$ of $\mathrm{P}(\mathrm{AN}-\mathrm{co}-\mathrm{MLA})$ reduces from ca. $168 \mathrm{~kJ} \mathrm{~mol}^{-1}$ to ca. $110 \mathrm{~kJ} \mathrm{~mol}^{-1}$, it is concluded that synthesized comonomer MLA can significantly improve stabilization of PAN, which is conducive to the preparation of high performance carbon fiber.

\section{Introduction}

Carbon fiber is a high-performance reinforcing material, which possesses excellent properties such as high strength, high modulus, good heat resistance and electrical conductivity. ${ }^{1,2}$ The composites of carbon fiber have been applied in many areas, such as transportation, architecture, the medical industry, sports equipment, defense areas and high-tech aerospace..$^{3-5}$ At present, three precursors, polyacrylonitrile fibers, pitch fibers and viscose fibers, can be employed to produce carbon fibers in industry, where polyacrylonitrile fibers are in a dominant position. However, polyacrylonitrile (PAN) homopolymer can't be used to prepare high strength carbon fiber in industry, owing to its poor stabilization such as high initiation temperature and rapid heat release. Thermal stabilization of PAN fibers is the key step in the production of carbonfibers. ${ }^{6-8}$ Usually, a small amount of acidic comonomer, such as acrylic

${ }^{a}$ College of Materials Science and Engineering, State Key Laboratory for Modification of Chemical Fibers and Polymer Materials, Donghua University, Shanghai 201620, China.E-mail: anqiju@163.com

${ }^{b}$ Key Laboratory of Science \& Technology of Eco-Textile, Ministry of Education, Donghua University, Shanghai 201620, China acid, ${ }^{9}$ methacrylic acid ${ }^{10}$ and itaconic acid (IA), ${ }^{11}$ was incorporated into a polymer chain to improve the stabilization of PAN homopolymer. Acid monomers can reduce the initiation temperature of stabilization and broaden the exothermic peak through ionic mechanism. ${ }^{12-14}$ What's more, the activation energy $\left(E_{\mathrm{a}}\right)$ of stabilization can be reduced significantly. Among acidic comonomers, IA is the most used one because it contains two carboxyl groups $(-\mathrm{COOH})$ which can initiate the intermolecular and intramolecular cyclization through ionic mechanism. The initiation temperature of cyclization has been reduced from $240{ }^{\circ} \mathrm{C}$ to $180{ }^{\circ} \mathrm{C} \cdot{ }^{15,16}$ The cyclization $E_{\mathrm{a}}$ of $\mathrm{P}(\mathrm{AN}-c o$-IA) has been splitted into two parts, the first part is assigned to ionic mechanisms about $104 \mathrm{~kJ} \mathrm{~mol}^{-1}$, which is much smaller than that of PAN homopolymer $\left(130 \mathrm{~kJ} \mathrm{~mol}^{-1}\right) .22,23$ The amount of IA can be reduced compared with other comonomer containing only one carboxy group, which is beneficial to preparing high performance carbon fiber. However, the carboxyl group of IA can capture the free radicals during polymerization process, resulting in the decrease of molecular weight, which limits the improvement of tensile strength of final carbon fiber. The acrylamide (AM) comonomer was also employed to improve the stabilization of PAN in many literatures, ${ }^{17-20}$ since the nitrogen of amide group $\left(-\mathrm{CONH}_{2}\right)$ can make a nucleophilic attack on adjacent carbon 
atoms of nitrile group, which can initiate the cyclization of PAN polymers at lower temperature through ionic mechanism and broaden the exothermic peaks. ${ }^{16,21}$

It is known that high molecular weight polyacrylonitrile precursor is the prerequisite for preparation of high performance carbon fiber. ${ }^{21-24}$ In this work, a bifunctional comonomer 2-methylenesuccinamic acid (MLA) with carboxyl group and amide group was synthesized to prepare poly(acrylonitrileco-2-methylenesuccinamic acid) [P(AN-co-MLA)]. Compared with IA, the amide group of the MLA replaces one of the carboxyl groups, which can reduce the probability of chain termination during polymerization process and improve molecular weight of PAN polymer effectively. ${ }^{25}$ The effects of monomer feed ratio on polymerization, polymer structure and stabilization were studied by elemental analysis (EA), Fourier transform infrared spectroscopy (FTIR), X-ray diffraction (XRD) and differential scanning calorimetry (DSC) in detail.

\section{Experimental}

\subsection{Materials}

Acrylonitrile (AN, analytical grade) was purchased from Shanghai Boer Chemical Reagent Co., Ltd. Shanghai, China. AN was distilled twice and stored in refrigerator before polymerization. Azodiisobutyronitrile (AIBN, analytical grade) was provided commercially by Sinopharm Chemical Reagent Co., Ltd. Shanghai, China and recrystallized twice by methanol. Dimethyl sulfoxide (DMSO, analytical grade) was received from Shanghai Huadong Reagent Company, Shanghai, China. 2Methylenesuccinamic acid (MLA) was synthesized in our laboratory. Itaconic acid (IA) and ammonium hydroxide (28 wt\%, analytical grade) were commercially supplied by Sinopharm Chemical Reagent Co., Ltd. Shanghai, China.

\subsection{Synthesis of bifunctional comonomer MLA}

$154 \mathrm{~g}$ ammonium hydroxide ( $28 \mathrm{wt} \%$ ) was added into a $1 \mathrm{~L}$ round-bottomed flask equipped with a mechanical stirrer. $98 \mathrm{~g}$ of IA was added slowly to the solution after cooling to $0{ }^{\circ} \mathrm{C}$, keeping the reaction temperature below $5{ }^{\circ} \mathrm{C}$. The mixture was warmed to room temperature when the addition of IA was completed. After stirring for $2 \mathrm{~h}$ the reaction mixture was cooled to $0{ }^{\circ} \mathrm{C}$ and the $\mathrm{pH}$ of it was adjusted to below 1 by adding $4 \mathrm{M}$ $\mathrm{H}_{2} \mathrm{SO}_{4}$ dropwise. After stirring for another $18 \mathrm{~h}$ under room temperature, the slurry was filtrated through a sintered glass frit at $0{ }^{\circ} \mathrm{C}$ and washed with $100 \mathrm{~mL}$ of dilute $\mathrm{H}_{2} \mathrm{SO}_{4}(\mathrm{pH}<3)$. The crude MLA was recrystallized by ethanol $(120 \mathrm{~mL})$ to get crystal.

Crystal, $52.7 \%$ yield. IR (KBr) $\nu_{\max } \mathrm{cm}^{-1}: 3359,3200\left(\mathrm{~N}-\mathrm{H}_{2}\right)$, 2934, $2901(\mathrm{C}-\mathrm{H}), 1704(\mathrm{C}=\mathrm{O}), 1668(\mathrm{C}=\mathrm{O}), 1640(\mathrm{C}=\mathrm{C}), 1433(\delta$ C-H), 1282, 1170 (C-O). ${ }^{1} \mathrm{H}-\mathrm{NMR}(400 \mathrm{~Hz}$, DMSO-d 6 , RT, TMS) $\delta$ ppm: $12.39(\mathrm{~s}, 1 \mathrm{H}, \mathrm{COOH}), 7.26,6.79\left(\mathrm{~s}, 2 \mathrm{H}, \mathrm{H}_{2} \mathrm{~N}\right), 6.09(\mathrm{~d}, J=$ $\left.0 \mathrm{~Hz}, 1 \mathrm{H}, \mathrm{CH}_{2}=\right), 5.64\left(\mathrm{~d}, J=0 \mathrm{~Hz}, 1 \mathrm{H}, \mathrm{CH}_{2}=\right), 3.07\left(\mathrm{~s}, 2 \mathrm{H}, \mathrm{CH}_{2}\right)$.

\subsection{Preparation of $\mathrm{P}(\mathrm{AN}-\mathrm{co}$-MLA)}

$\mathrm{P}$ (AN-co-MLA) copolymer with different feed ratio of AN/MLA = 99/1, 98/2, 97/3, 96/4, 95/5 (wt/wt) was prepared at $60{ }^{\circ} \mathrm{C}$ under nitrogen atmosphere using DMSO as solvent and AIBN as initiator. The monomer concentration was $24 \mathrm{wt} \%$ and initiator content was $0.8 \mathrm{wt} \%$ of monomer. A typical polymerization for feed ratio AN/MLA = 99/1 (wt/wt) is given below: $10.00 \mathrm{~mL}$ of AN, $0.1966 \mathrm{~g}$ of MLA, $23.60 \mathrm{~mL}$ of DMSO and $0.0656 \mathrm{~g}$ of AIBN were added into a $250 \mathrm{~mL}$ three-necked flask fitted with a condenser tube and stirrer. After 24 hours of polymerization, the reaction mixture was poured into excessive methanol to precipitate the polymer. The isolated polymer was washed with methanol for $4-5$ times and then dried at $60{ }^{\circ} \mathrm{C}$ under vacuum to a constant weight. For comparison, PAN homopolymer and poly(acrylonitrile-methyl acrylate-acrylic acid) [P(AN-MA-AA)] with feed ratios AN/MA/AA = 98/2/2 was also prepared by solution polymerization in this work.

\subsection{Characterization}

Fourier transform infrared spectroscopy (FTIR) spectra was recorded on a Nicolet 8700 FTIR spectrophotometer at room temperature using transmission method; $1 \mathrm{mg}$ powder sample was mixed thoroughly with $100 \mathrm{mg} \mathrm{KBr}$ and pelletized for FTIR characterization; 32 scans were collected at a resolution of $1 \mathrm{~cm}^{-1}$ and the wavelength region is 400 to $4000 \mathrm{~cm}^{-1}$.

DSC curves were carried out on a Modulated DSC 2910. Five metals (In, Hg, Sn, Bi, Zn) was employed for temperature and heat flow calibrations. The melting point of metals was used for temperature calibration and the melting area was used for heat flow calibration. 5-10 mg samples were scanned at different heating rates (i.e. $5,10,15,20,30{ }^{\circ} \mathrm{C} \min ^{-1}$ ) in $\mathrm{N}_{2}$ atmosphere $\left(40 \mathrm{~mL} \mathrm{~min}^{-1}\right)$.

Elementar vario EL III elemental analyzer was employed to determine the content of carbon $(\mathrm{C})$, nitrogen $(\mathrm{N})$, hydrogen $(\mathrm{H})$ and oxygen $(\mathrm{O})$ of $\mathrm{P}(\mathrm{AN}-\mathrm{co}$-MLA) copolymers.

The monomer reactivity ratios were calculated from the element analysis results.

$\mathrm{X}$-ray diffraction (XRD) patterns of powered samples were measured on a Rigaku D/max-2550 diffractometer using nickelfiltered $\mathrm{Cu} \mathrm{K}-\alpha$ radiation (wavelength: $0.154 \mathrm{~nm}$ ) in the range $3-50^{\circ}$ at the rate of $1^{\circ} \mathrm{min}^{-1}$. The current and voltage values is $200 \mathrm{~mA}$ and $40 \mathrm{kV}$, respectively. All the XRD measurements were carried out under the same conditions. The crystalline planar spacing $d$ and crystallite size of the laterally order domains $\left(L_{\mathrm{c}}\right)$ were estimated by the Scherrer equation and Bragg equation as follows: ${ }^{26}$

$$
\begin{aligned}
d & =\frac{\lambda}{2 \sin \theta} \\
L_{\mathrm{c}} & =\frac{k \lambda}{B \cos \theta}
\end{aligned}
$$

where $\lambda=0.154056 \mathrm{~nm}$ is the wavelength of $\mathrm{CuK}_{\alpha} \mathrm{X}$-ray, $\theta$ is the Bragg angle, $B$ is the full width at half maximum intensity (FWHM) of the peak around $2 \theta=17^{\circ}$, and $k$ is a constant 0.89 . The crystallinity (CI) was determined by Bell and Dumbleton method: ${ }^{26}$

$$
\mathrm{CI}=\frac{A_{\mathrm{c}}}{\left(A_{\mathrm{c}}+A_{\mathrm{a}}\right)}
$$

where $A_{\mathrm{c}}$ is the integral area of crystalline zone around $2 \theta=17^{\circ}$ in XRD patterns, and $A_{\mathrm{a}}$ is the integral area of amorphous zone. $A_{\mathrm{c}}$ was calculated using straight line segments from $2 \theta=11^{\circ}$ to 
$2 \theta=21^{\circ}$ as the baseline, while the total integral area $A\left(A=\left(A_{\mathrm{c}}+A_{\mathrm{a}}\right)\right)$ using straight line segments from $2 \theta=11^{\circ}$ to $2 \theta=32^{\circ}$ as the baseline.

The viscosity-average molecular weight $\left(M_{\eta}\right)$ of the $\mathrm{P}(\mathrm{AN}-\mathrm{co}$ MLA) copolymers was measured in a $(50 \pm 0.5){ }^{\circ} \mathrm{C}$ water bath using Ubbelohde viscometer method as follows: $0.20 \mathrm{~g}$ of P(AN-co-MLA) copolymer was dissolved in $15 \mathrm{~mL}$ DMSO solvent. $10 \mathrm{~mL}$ of $\mathrm{P}(\mathrm{AN}-$ co-MLA) solution was injected into Ubbelohde viscometer, the efflux time of $\mathrm{P}(\mathrm{AN}-\mathrm{co}$-MLA) solution was measured and named as $t_{1}$. Then, $5 \mathrm{~mL}$ of DMSO was added into the above P(AN-co-MLA) solution, measuring the efflux time $t_{2}$ of mixture. The efflux time $t_{3}$, $t_{4}, t_{5}$ was obtained by adding $10 \mathrm{~mL}, 10 \mathrm{~mL}, 10 \mathrm{~mL}$ DMSO solvent in Ubbelohde viscometer. The equation is expressed as follows:

$$
\begin{gathered}
\eta_{\mathrm{r}}=\frac{t}{t_{0}} \\
\eta_{\mathrm{sp}}=\eta_{\mathrm{r}}-1=\frac{t-t_{0}}{t_{0}}
\end{gathered}
$$

where $t_{0}$ is the efflux time of the DMSO, $\eta_{\mathrm{r}}$ is relative viscosity, $\eta_{\mathrm{sp}}$ is specific viscosity. A series of $\ln \left(\eta_{\mathrm{r}} / c\right)$ and $\eta_{\mathrm{sp}} / c$ were calculated at different concentrations $(c)$. The plots of $\ln \left(\eta_{\mathrm{r}} / c\right)$ versus $c$ and $\eta_{\mathrm{sp}} / c$ versus $c$ give straight lines. The intrinsic viscosity $[\eta]$ is calculated by linear extrapolation of $c$ to zero. The viscosity average molecular weight $M_{\eta}$ was determined by the following equation:

$$
[\eta]=2.83 \times 10^{-2} M_{\eta}^{0.758}
$$

For heat treatment, the power sample was heated at different temperatures in an air oven with a temperature accuracy of $1^{\circ} \mathrm{C}$. First, the air oven was heated to the setting temperatures (i.e. $160,180,185,200,220,240,260,280{ }^{\circ} \mathrm{C}$ ), then the powder samples were put into the air oven and heated at the constant temperature for $30 \mathrm{~min}$.

\section{Results and discussion}

\subsection{The molecular weight and conversion rate}

The effect of monomer feed ratio (AN/MLA) on the polymerization conversion and the molecular weight of $\mathrm{P}(\mathrm{AN}-\mathrm{co}-\mathrm{MLA})$ is shown in Fig. 1. As MLA content in the monomer feed ratio increases, both the polymerization conversion and molecular weight of $\mathrm{P}(\mathrm{AN}-$ co-MLA) reduce significantly. The molecular volume and steric hindrance of MLA are larger than that of AN, which impedes propagating of chain radicals and results in the decrease of molecular weight and conversion. ${ }^{8}$ It is well known that the molecular weight of acrylonitrile copolymers has a significant effect on the properties of carbon fibers. In order to get high molecular weight $\mathrm{P}(\mathrm{AN}-\mathrm{co}-\mathrm{MLA})$, the amounts of comonomer in the feed should be controlled less than $3.0 \mathrm{wt} \%$ based on total monomers. $^{27}$

\subsection{Reactivity ratio studies}

According to the mechanism of free radical polymerization, the molar fraction of MLA in $\mathrm{P}(\mathrm{AN}-\mathrm{co}-\mathrm{MLA})$ can be calculated by the

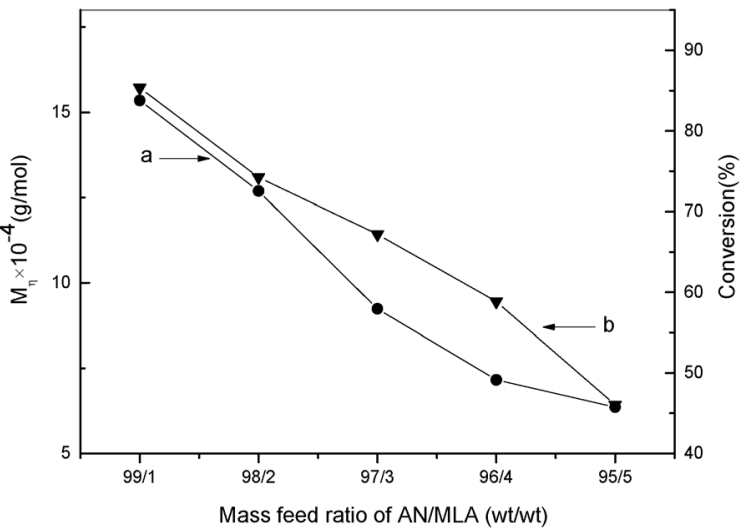

Fig. 1 Effect of monomer feed ratio on the conversion of polymerization and molecular weight: (a) molecular weight, (b) the conversion rate.

Table 1 Parameters for solution copolymerization of AN/MLA under low conversion

\begin{tabular}{lllll}
\hline $\begin{array}{l}\text { AN/MLA } \\
\text { in the feed } \\
(\mathrm{wt} / \mathrm{wt})\end{array}$ & $\begin{array}{l}X^{a} \\
\left(\mathrm{~mol} \mathrm{~mol}^{-1}\right)\end{array}$ & $\begin{array}{l}\text { Conversion } \\
(\%)\end{array}$ & $\begin{array}{l}\text { O content } \\
\text { in the } \\
\text { copolymers } \\
(\mathrm{wt} \%)\end{array}$ & $\begin{array}{l}Y^{b} \\
\left(\mathrm{~mol} \mathrm{~mol}^{-1}\right)\end{array}$ \\
\hline $99 / 1$ & 240.89 & 5.34 & 0.648 & 137.328 \\
$98 / 2$ & 119.22 & 6.28 & 1.291 & 67.718 \\
$97 / 3$ & 78.67 & 5.52 & 1.919 & 44.760 \\
$96 / 4$ & 58.39 & 5.43 & 2.548 & 33.110 \\
$95 / 5$ & 46.23 & 6.09 & 3.162 & 26.208 \\
${ }^{a} X=\left[M_{1}\right] /\left[M_{2}\right] \cdot{ }^{b} Y=\mathrm{d}\left[M_{1}\right] / \mathrm{d}\left[M_{2}\right]$. & &
\end{tabular}

following equation with the end-group effect on the polymer ignored:

$$
[\mathrm{MLA}]=\frac{C_{\mathrm{O}} /(3 \times 16)}{\frac{1-\left(C_{\mathrm{O}} \times 129\right) /(3 \times 16)}{53}+\frac{C_{\mathrm{O}}}{3 \times 16}}=\frac{53 C_{\mathrm{O}}}{48-76 C_{\mathrm{O}}}
$$

where $C_{\mathrm{O}}$ is the oxygen content of $\mathrm{P}(\mathrm{AN}-\mathrm{co}$-MLA) copolymers. From the elemental analysis of oxygen, the molar fraction ratios of AN/MLA in the P(AN-co-MLA) copolymers can be obtained, which is used to calculate the reactivity ratio of AN and MLA by Fineman-Rossand Kelen-Tüdõs methods. Table 1 shows parameters for solution copolymerization of AN/MLA under low conversion.

According to the Mayo-Lewis equation, the Fineman-Ross method is depicted as follows:

$$
G=r_{1} H-r_{2}
$$

$G$ and $H$ are represented by

$$
G=X(Y-1) / Y
$$

where $X$ and $Y$ are the molar fraction ratios of AN/MLA in the feed and in the $\mathrm{P}(\mathrm{AN}-\mathrm{co}$-MLA) copolymers, respectively: 


$$
X=\left[M_{1}\right] /\left[M_{2}\right] \text { and } Y=\mathrm{d}\left[M_{1}\right] / \mathrm{d}\left[M_{2}\right]
$$

The plot of $G$ versus $H$ gives a straight line with the slope as $r_{1}$ and the intercept of the $Y$ axis as $r_{2}$.

The equations proposed by Kelen and Tüdõs method are expressed as follows:

$$
\eta=\left(r_{1}+\frac{r_{2}}{\alpha}\right) \xi-\frac{r_{2}}{\alpha}
$$

$\eta$ and $\xi$ are represented by

$$
\eta=G /(\alpha+H) \text { and } \xi=H /(\alpha+H)
$$

$\alpha$ is an arbitrary constant and represented by

$$
\alpha=\left(H_{\mathrm{m}} H_{\mathrm{M}}\right)^{-1 / 2}
$$

where $H_{\mathrm{m}}$ and $H_{\mathrm{M}}$ is the lowest and highest values calculated from the series of measurements. The plot of $\eta$ versus $\xi$ gives a straight line. The extrapolation of the line to $\xi=1$ gives $r_{1}$ and to 0 gives $r_{2} / \alpha$.

As shown in the Fig. 2, the reactivity ratios computed by Fineman-Ross agrees well with that obtained by Kelen-Tüdõs and the reactivity ratio of MLA is larger than that of AN, indicating that the reactivity of comonomer MLA is higher than that

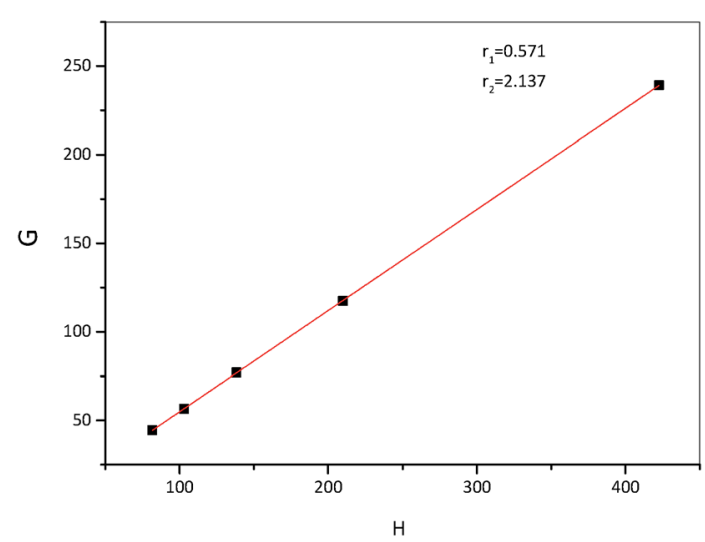

(1) Fineman-Ross method

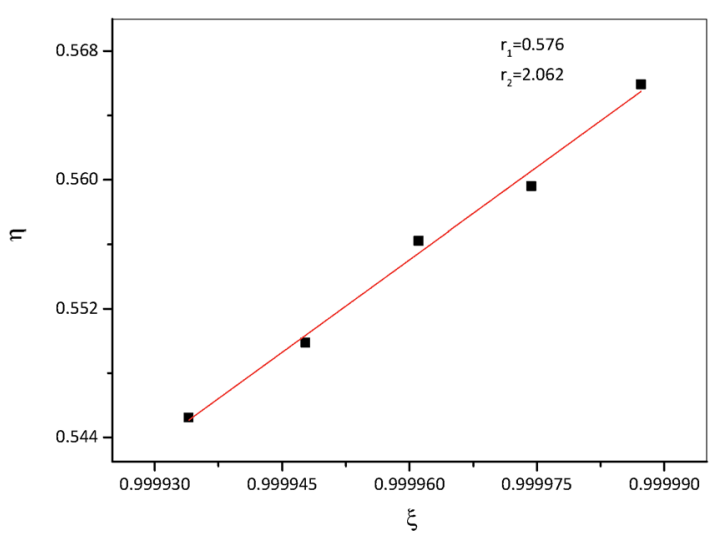

(2) Kelen-tudos method

Fig. 2 Fineman-Ross (1) and Kelen-Tüdõs (2) methods used to calculate monomer reactivity ratios.

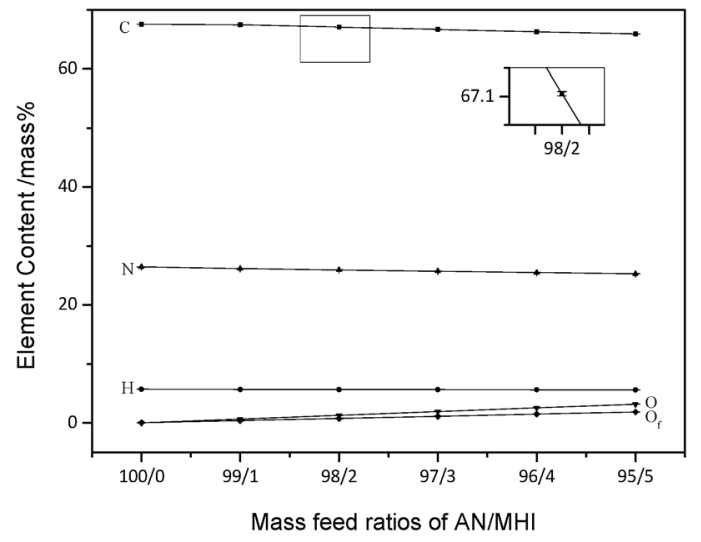

Fig. 3 Elemental analysis of $\mathrm{P}(\mathrm{AN}-\mathrm{CO}-\mathrm{MLA})$ copolymers with different feed ratios of $A N / M L A$ : $O_{f}, O$ content in the feed.

of AN. Therefore, more comonomer MLA is incorporated into the polymer chain than AN. Which was confirmed by the following elemental results that the content of MLA in the P(ANco-MLA) copolymer is higher than in the feed. ${ }^{28,29}$

\subsection{Elemental analysis}

The acetanilide was used as a standard to analyze the elemental content of [P(AN-co-MLA)] copolymers. Two readings were obtained during the collection of elemental analysis data and the standard deviation is less than $3 \%$. Fig. 3 shows the elemental analysis of the $\mathrm{P}(\mathrm{AN}-\mathrm{co}$-MLA) copolymers with different feed ratios of AN/MLA. The $\mathrm{O}$ content in $\mathrm{P}(\mathrm{AN}-\mathrm{co}$-MLA) becomes larger with the increase of MLA content in the feed, manifesting the increase of MLA content in P(AN-co-MLA), because the $\mathrm{O}$ element is only provided by the comonomer MLA. However, all other element $\mathrm{C}, \mathrm{N}$ and $\mathrm{H}$ contents decrease with the increase of MLA content in the feed. In addition, the $\mathrm{O}$ content in the feed $\left(\mathrm{O}_{\mathrm{f}}\right)$ is also shown, it can be found that the $\mathrm{O}$ content in $\mathrm{P}$ (AN-coMLA) copolymer is larger than $\mathrm{O}_{\mathrm{f}}$, indicating that more MLA was incorporated in the polymer chains than in the feed, which is consistent with the above reactivity ratio results. ${ }^{30}$

\subsection{FTIR studies}

Fig. 4(1) shows the FTIR spectra of PAN and P (AN-co-MLA) copolymer with different mass feed ratios. The peak at $2244 \mathrm{~cm}^{-1}$ is assigned to the stretching vibration of $\mathrm{C} \equiv \mathrm{N}$ acrylonitrile unit in the polymer chain. The peak at 1721 and $1678 \mathrm{~cm}^{-1}$ belong to stretching vibration of $\mathrm{C}=\mathrm{O}$ and amide groups, respectively. ${ }^{31,32}$ Obviously, the $\mathrm{C}=\mathrm{O}$ and $\mathrm{NH}_{2}$ groups only exist in the MLA comonomer, the appearance of $1721 \mathrm{~cm}^{-1}$ and $1678 \mathrm{~cm}^{-1}$ peaks in Fig. 4(1)(b)-(d) indicates the comonomer MLA copolymerizes with AN successfully. The intensity of peak at $1721 \mathrm{~cm}^{-1}$ and $1678 \mathrm{~cm}^{-1}$ becomes larger with the increase of MLA content in the feed, indicating more MLA was incorporated in the polymer chains. The content of MLA in $\mathrm{P}(\mathrm{AN}-\mathrm{co}$-MLA) copolymer can be controlled by the monomer feed ratio. For all P(AN-co-MLA) copolymer, the intensity of peak at $2244 \mathrm{~cm}^{-1}$ attributed to $\mathrm{C} \equiv \mathrm{N}$ stretching vibration keeps unchanged, suggesting that long uninterrupted sequences of 


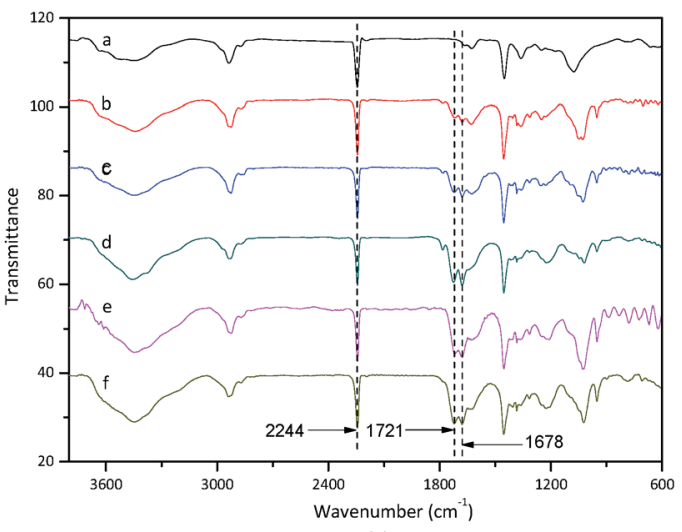

(1)

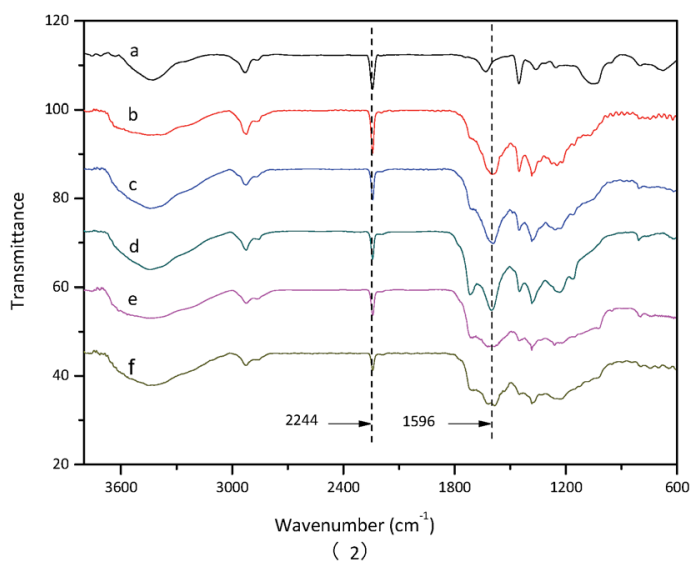

Fig. 4 FTIR spectra of PAN and P(AN-CO-MLA) copolymers with different feed ratios (1) original and (2) stabilized $185^{\circ} \mathrm{C}$ for 30 minutes: (a) PAN, (b) AN/MLA = 99/1 (wt/wt), (c) AN/MLA = 98/2 (wt/wt), (d) AN/MLA $=97 / 3$ (wt/wt), (e) AN/MLA = 96/4 (wt/wt), (f) AN/MLA = 95/5 (wt/wt).

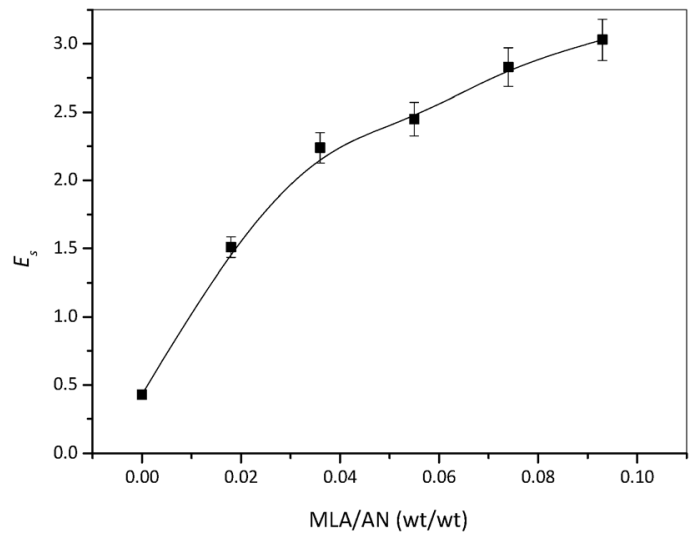

Fig. 5 Effect of MLA/AN (wt/wt) in P(AN-CO-MHI) on the extent of stabilization $\left(E_{\mathrm{s}}\right)$.

AN unit are present in polymer chains of all $\mathrm{P}(\mathrm{AN}-\mathrm{co}$-MLA) copolymers. The intensity of bending vibration $\left(1454 \mathrm{~cm}^{-1}\right)$ of $\mathrm{CH}_{2}$ and stretching vibration $\left(2939 \mathrm{~cm}^{-1}\right)$ of $\mathrm{CH}, \mathrm{CH}_{2}$ groups do not show obvious changes.

Fig. 4(2) show FTIR spectra of PAN and P(AN-co-MLA) copolymers with different compositions stabilized at $185{ }^{\circ} \mathrm{C}$ for
30 minutes in air atmosphere. It is well known that a few exothermic reactions occur during stabilization process, such as cyclization, dehydrogenation and oxidation. The cyclization reactions convert $\mathrm{C} \equiv \mathrm{N}$ structure into the $\mathrm{C}=\mathrm{N}$ structure and dehydrogenating reactions convert $\mathrm{C}-\mathrm{C}$ structure into $\mathrm{C}=\mathrm{C}$ structure, which are the most important two reactions for preparation of high performance carbon fiber. As shown in Fig. 4(2), the intensity of peak at $2244 \mathrm{~cm}^{-1}$ (stretching vibration of $\mathrm{C} \equiv \mathrm{N}$ ) decreases with the increase of MLA content in the feed, confirming more $\mathrm{C} \equiv \mathrm{N}$ structure convert into $\mathrm{C}=\mathrm{N}$ structure and the synthesized comonomer MLA can improve effectively the cyclization reaction. The peak at $1596 \mathrm{~cm}^{-1}$ is assigned to stretching vibration bands of $\mathrm{C}=\mathrm{C}$ (due to dehydrogenation reaction) conjugated with $\mathrm{C}=\mathrm{N}$ (due to cyclization reaction). As MLA content increases in the feed, the intensity of conjugated stretching bands strengthens. This means both cyclization and dehydrogenation have been promoted by the comonomer MLA. In order to evaluate the extent of stabilization, the parameter was defined by using intensity changes of bonds at $2244 \mathrm{~cm}^{-1}$ and $1596 \mathrm{~cm}^{-1}$ as follows: ${ }^{11}$

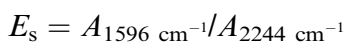

where $A$ is the absorbance intensity defined as $A=\log \left(T_{0} / T\right), T_{0}$ and $T$ are the transmittances at baseline and maximum, respectively. According to Lambert-Beer's law: $A=a b c$, where $a$ is the molar absorption coefficient, $b$ is the thickness of the $\mathrm{KBr}$ pellet, and $c$ is the molar concentration of sample solution. Both the absorbance intensity of bands at $2244 \mathrm{~cm}^{-1}$ and $1596 \mathrm{~cm}^{-1}$ are determined by using the same sample, namely with the same $b$ value. Therefore, the intensity ratio of the two absorption peaks at $1596 \mathrm{~cm}^{-1}$ and $2244 \mathrm{~cm}^{-1}$ is approximately equal to the ratio of the content of the generated $\mathrm{C}=\mathrm{N}$ and $\mathrm{C}=\mathrm{C}$ to the residual $\mathrm{C} \equiv \mathrm{N}$ group.

The MLA/AN (wt/wt) in P(AN-co-MLA) was calculated based on the element analysis above. The effect of MLA/AN (wt/wt) in $\mathrm{P}$ (AN-co-MLA) on the extent of stabilization $\left(E_{\mathrm{s}}\right)$ is shown in Fig. 5. The extent of stabilization increases significantly with the increase of MLA content in the P(AN-co-MLA) copolymer. The cyclization reaction of $\mathrm{P}(\mathrm{AN}-\mathrm{co}$-MLA) copolymer can be initiated by free radical mechanism and ionic mechanism, because the carboxyl oxygen and amide nitrogen of in MLA comonomer can make nucleophilic attack on the carbon atom of an adjacent nitrile group and then induce molecules to cyclize. ${ }^{33}$ The bifunctional comonomer MLA provides nitrile groups with more opportunities to cyclize than PAN homopolymer through ionic mechanism, thus the $E_{\mathrm{s}}$ values becomes larger with increase of MLA content in the P(AN-co-MLA).

\subsection{XRD studies}

Fig. 6(1) shows the XRD patterns of P(AN-co-MLA) copolymers with different feed ratios. There are two peaks in the XRD patterns, a stronger diffraction peak at about $2 \theta=17^{\circ}$ assigned to (100) crystalline plane of the pseudohexagonal cell and a weak diffraction peak at about $2 \theta=29^{\circ}$ assigned to the (101) crystalline plane of the pseudohexagonal cell. ${ }^{34}$ The intensity of peak $\left(2 \theta=17^{\circ}\right)$ decreases with the increase of MLA content in 


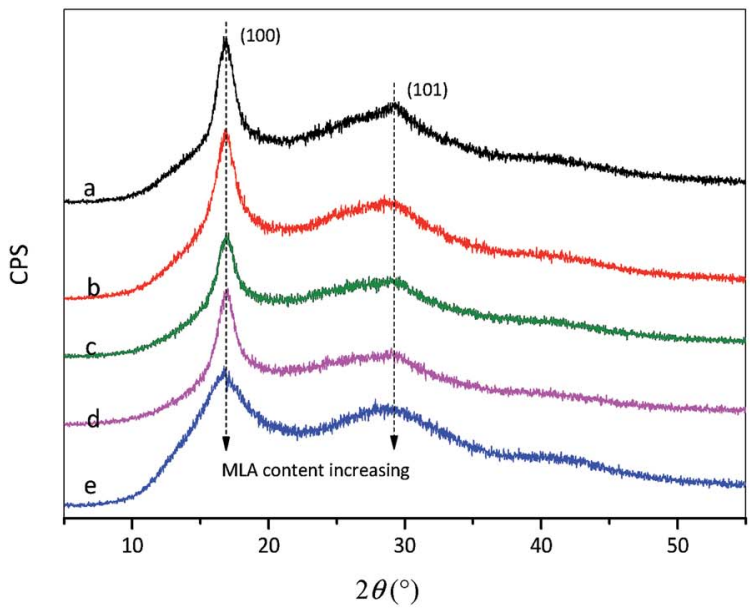

(1)

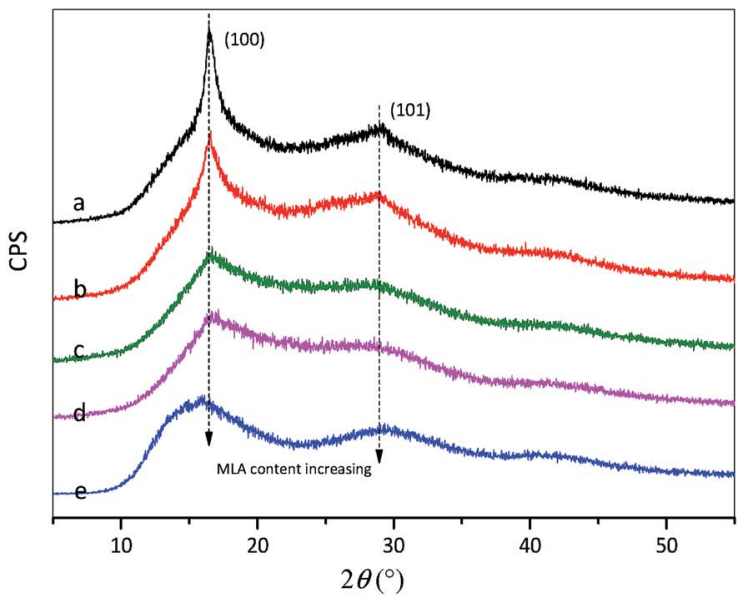

(2)

Fig. 6 XRD patterns of $\mathrm{P}(\mathrm{AN}-\mathrm{CO}-\mathrm{MLA})$ copolymers with different MLA/AN compositions (1) original and (2) stabilized $185^{\circ} \mathrm{C}$ for 30 minutes: (a)

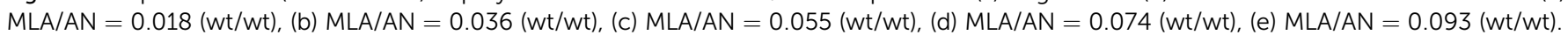

Table 2 XRD analysis results of P(AN-co-MLA) copolymers with different compositions according to Fig. $6^{a}$

\begin{tabular}{llllrr}
\hline $\begin{array}{l}\text { MLA/AN in polymers } \\
(\mathrm{wt} / \mathrm{wt})\end{array}$ & Peak $\left(^{\circ}\right)$ & Peak intensity (CPS) & FWHW $\left(^{\circ}\right)$ & $d(\mathrm{~nm})$ & $L_{\mathrm{c}}(\mathrm{nm})$ \\
\hline 0.018 & 16.89 & 718 & 0.893 & 0.530 & 9.193 \\
0.036 & 17.01 & 540 & 0.898 & 0.526 & 9.148 \\
0.055 & 16.89 & 487 & 0.862 & 0.530 & 46.94 \\
0.074 & 16.62 & 458 & 0.950 & 0.539 & 8.624 \\
0.093 & 16.72 & 259 & 0.697 & 0.536 & 43.93 \\
\end{tabular}

${ }^{a}$ where FWHM is the full width at half maximum intensity. $d$ is the crystalline planar spacing. $L_{\mathrm{c}}$ is crystallite size of the laterally order domains. CI is the crystallinity of $\mathrm{P}(\mathrm{AN}-\mathrm{co}$-MLA) copolymers.

$\mathrm{P}(\mathrm{AN}-\mathrm{co}$-MLA) copolymers because of the incorporation of MLA into polymer chains. XRD patterns of $\mathrm{P}(\mathrm{AN}-c o-\mathrm{MLA})$ were processed by Origin 8.5 software to analyze the peak center, peak area and the FWHM of peak around $2 \theta=17^{\circ}$. The crystalline planar spacing $d$, crystallite size $L_{\mathrm{c}}$ and crystallinity CI was calculated and summarized in Table 2. The crystallinity index CI of the P(AN-coMLA) copolymer is smaller than that of PAN homopolymer $(50.24 \%)$ reported in our previous work, ${ }^{35}$ and decreases with the increase of MLA content in P(AN-co-MLA) copolymer. The reason is that the incorporation of MLA into polymer chain blocks the interaction between $\mathrm{C} \equiv \mathrm{N}$ groups and as a result of reducing form of CI. The XRD patterns of P(AN-co-MLA) heated at $185{ }^{\circ} \mathrm{C}$ for 30 minutes in an air atmosphere are shown in Fig. 6(2). The stabilization is a process that converting linear structure to ladder structure, and the structural changes during the stabilization agree well with the intensity changes of the peak around $2 \theta=17^{\circ} .{ }^{36}$ Thus, the peak intensity around $2 \theta=17^{\circ}$ can be used to represent the extent of stabilization, the formula is as follows: ${ }^{37}$

$$
\mathrm{SI}=\left(I_{0}-I_{\mathrm{s}}\right) / I_{\mathrm{S}}
$$

where $I_{0}$ is the intensity of peak around $2 \theta=17^{\circ}$ from the original polymer, and $I_{\mathrm{s}}$ is the intensity of peak around $2 \theta=17^{\circ}$ from the polymer stabilized for $30 \mathrm{~min}$.
As shown in Table 3, the SI value (-8.36\%) of P(AN-co-MLA) with $\mathrm{MLA} / \mathrm{AN}=0.018$ is negative, the similar as PAN $(-113.56 \%)$ in our previous work. ${ }^{38}$ From the following DSC analysis (DSC studies section), it is known that the stabilization reactions of PAN homopolymer and P(AN-co-MLA) with MLA/AN $=0.018$ have not yet started significantly at $185^{\circ} \mathrm{C}$, however the energy provided by heating is enough to break the boundaries between crystalline zones and amorphous zones, which results in further crystallization of $\mathrm{P}(\mathrm{AN}-\mathrm{co}$-MLA) and the increase of intensity of (100) peak, so the SI value of PAN is negative. Although the SI for $\mathrm{P}(\mathrm{AN}-c o-\mathrm{MLA})$ with MLA/AN $=0.018$ is

Table 3 SI results P(AN-co-MLA) copolymers with different compositions corresponding to Fig. 6

\begin{tabular}{lllll}
\hline $\begin{array}{l}\text { MLA/AN in } \\
\text { polymers } \\
\text { (wt/wt) }\end{array}$ & Peak $\left(^{\circ}\right)$ & $\begin{array}{l}\text { Peak intensity } \\
I_{0}(\mathrm{CPS})\end{array}$ & $\begin{array}{l}\text { Peak intensity } \\
I_{\mathrm{S}}(\mathrm{CPS})\end{array}$ & SI (\%) \\
\hline 0.018 & 16.43 & 718 & 778 & -8.36 \\
0.036 & 16.58 & 540 & 472 & 12.59 \\
0.055 & 16.21 & 487 & 142 & 70.84 \\
0.074 & 16.65 & 458 & 155 & 66.16 \\
0.093 & 14.83 & 259 & 112 & 56.76
\end{tabular}




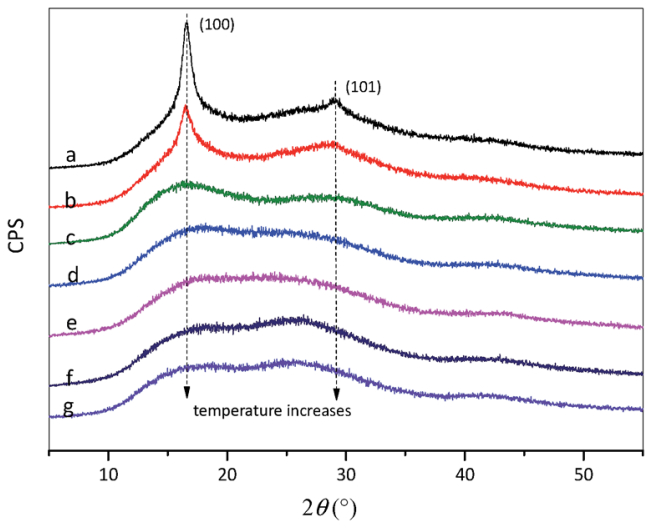

Fig. 7 XRD patterns of $\mathrm{P}(\mathrm{AN}-\mathrm{CO}-\mathrm{MLA})$ copolymers with $\mathrm{MLA} / \mathrm{AN}=$ 0.036 (wt/wt) at different temperatures for 30 minutes (a) $160{ }^{\circ} \mathrm{C}$, (b) $180^{\circ} \mathrm{C}$, (c) $200^{\circ} \mathrm{C}$, (d) $220^{\circ} \mathrm{C}$, (e) $240{ }^{\circ} \mathrm{C}$, (f) $260^{\circ} \mathrm{C}$, (g) $280^{\circ} \mathrm{C}$.

negative, it is much larger than that of PAN, confirming the improvement of stabilization by MLA. When the MLA/AN is larger than 0.0036 , the SI is positive and the stabilization dominate the intensity of peak around $2 \theta=17^{\circ}$ rather than crystallization, because the MLA can reduce significantly the cyclization initiation temperature as shown in following DSC curves. When more MLA incorporating the polymer chain of PAN, the SI become smaller due to the large molecular volume of MLA.

In order to study the effect of heating temperature on stabilization of $\mathrm{P}(\mathrm{AN}-c o-\mathrm{MLA})$. The $\mathrm{P}(\mathrm{AN}-c o-\mathrm{MLA})$ copolymer with MLA/AN $=0.036$ was stabilized at different temperature for $30 \mathrm{~min}$ and the XRD patterns of them are shown in Fig. 7. The SI was calculated using eqn (15) based on Fig. 7 and compiled in Table 4 . When the heating temperature is lower than $200^{\circ} \mathrm{C}$, the stabilization has not yet started obviously, the SI is negative due to the further crystallization of $\mathrm{P}(\mathrm{AN}-c o-\mathrm{MLA})$. The heating temperature is $\geq 200^{\circ} \mathrm{C}$, the peak intensity of $2 \theta=17^{\circ}$ decrease significantly, the peak around $2 \theta=29^{\circ}$ disappears and a new diffracting diffraction peak about $2 \theta=25.5^{\circ}$ appears, all these phenomena confirming the polymer chains of $\mathrm{P}(\mathrm{AN}-\mathrm{co}$-MLA) have been converted from linear structure to ladder structure. The SI has a great rise at $200^{\circ} \mathrm{C}$, after this the $I_{\mathrm{S}}$ increases slowly, indicating that most of the stabilization reactions have been completed under $200{ }^{\circ} \mathrm{C}$ for $30 \mathrm{~min}$. The reason is that the

Table 4 SI results $\mathrm{P}(\mathrm{AN}-\mathrm{CO}-\mathrm{MLA})$ copolymers with $\mathrm{MLA} / \mathrm{AN}=0.036$ heated at different temperatures for 30 min corresponding to Fig. 7

\begin{tabular}{lllll}
\hline $\begin{array}{l}\text { Heat treatment } \\
\text { temperature }\end{array}$ & Peak $\left({ }^{\circ}\right)$ & $\begin{array}{l}\text { Peak intensity } \\
I_{0}(\mathrm{CPS})\end{array}$ & $\begin{array}{l}\text { Peak intensity } \\
I_{\mathrm{S}}(\mathrm{CPS})\end{array}$ & SI (\%) \\
\hline $160{ }^{\circ} \mathrm{C}$ & 16.58 & 540 & 1202 & -122.59 \\
$180^{\circ} \mathrm{C}$ & 16.50 & 540 & 584 & -8.15 \\
$200{ }^{\circ} \mathrm{C}$ & 16.57 & 540 & 89 & 83.52 \\
$220{ }^{\circ} \mathrm{C}$ & 17.95 & 540 & 70 & 87.04 \\
$240{ }^{\circ} \mathrm{C}$ & 18.38 & 540 & 61 & 88.70 \\
$260{ }^{\circ} \mathrm{C}$ & 18.34 & 540 & 56 & 89.62 \\
$280^{\circ} \mathrm{C}$ & 18.51 & 540 & 52 & 90.37
\end{tabular}

cyclization initiation temperature of $\mathrm{P}(\mathrm{AN}-\mathrm{co}$-MLA) has been reduced greatly from $244.16^{\circ} \mathrm{C}$ to $176.49^{\circ} \mathrm{C}$ compared with PAN homopolymer, which can be found in the following DSC studies.

\subsection{DSC studies}

Fig. 8 shows the DSC curves of PAN, P(AN-MA-AA) with feed ratio of $\mathrm{AN} / \mathrm{MA} / \mathrm{AA}=98 / 2 / 2$ and $\mathrm{P}(\mathrm{AN}-c o-\mathrm{MLA})$ copolymers with different compositions heated from ambient temperature to $350{ }^{\circ} \mathrm{C}$ in $\mathrm{N}_{2}$ atmosphere $\left(40 \mathrm{~mL} \mathrm{~min}{ }^{-1}\right)$. The parameters obtained from the exotherms, including the temperature of initiation $\left(T_{\mathrm{i}}\right)$, the temperature of termination $\left(T_{\mathrm{f}}\right)$ and their difference $\left(\Delta T=T_{\mathrm{f}}-T_{\mathrm{i}}\right)$, the first peak temperature $\left(T_{\mathrm{p} 1}\right.$, the peak at lower temperature), the second peak temperature $\left(T_{\mathrm{p} 2}\right.$, the peak at higher temperature), the third peak temperature $\left(T_{\mathrm{p} 3}\right.$, the peak at highest temperature), the evolved heat $(\Delta H)$, and the velocity of evolving heat $(\Delta H / \Delta T)$, are listed in Table 5 .

The oxygen is absent during the DSC test, therefore no oxidation reaction occurs and the exothermic peaks of the acrylonitrile polymer is attributed to cyclization reactions. ${ }^{39}$ As shown in Fig. 8, the PAN homopolymer exhibits a sharp single exothermic peak, and the stabilization initiation temperature is as high as $244^{\circ} \mathrm{C}$. The cyclization of PAN can only be initiated through free radical mechanism at high temperature, a large amount of heat is released at a short time, which results in breakage of the molecular chain during stabilization and eventually inherits defects to the carbon fiber. Compared with PAN homopolymer, the initiation temperature of $\mathrm{P}(\mathrm{AN}-\mathrm{MA}-\mathrm{AA})$ decreased from $244^{\circ} \mathrm{C}$ to $206^{\circ} \mathrm{C}$, and $\Delta H / \Delta T$ value is reduced from $34.01 \mathrm{~J} \mathrm{~g}^{-1}{ }^{\circ} \mathrm{C}^{-1}$ to $15.18 \mathrm{~J} \mathrm{~g}^{-1}{ }^{\circ} \mathrm{C}^{-1}$. However, the $\Delta H$ of $\mathrm{P}(\mathrm{AN}-\mathrm{MA}-\mathrm{AA})$ is smaller than that of $\mathrm{P}(\mathrm{AN}-\mathrm{co}-$ MLA) as shown in Table 5, indicating fewer cyclization reaction occurs, it is not conducive to the stabilization reaction. The DSC curve of $\mathrm{P}(\mathrm{AN}-\mathrm{co}$-MLA) copolymer has two or even three exothermic peaks, which broadens the exothermic peak and avoids the centralized heat release. The appearance of new exothermic peaks at the lower temperature is attributed to the cyclization reactions initiated by ionic mechanism. As shown in Fig. 9, both the carboxyl oxygen and amide nitrogen in MLA

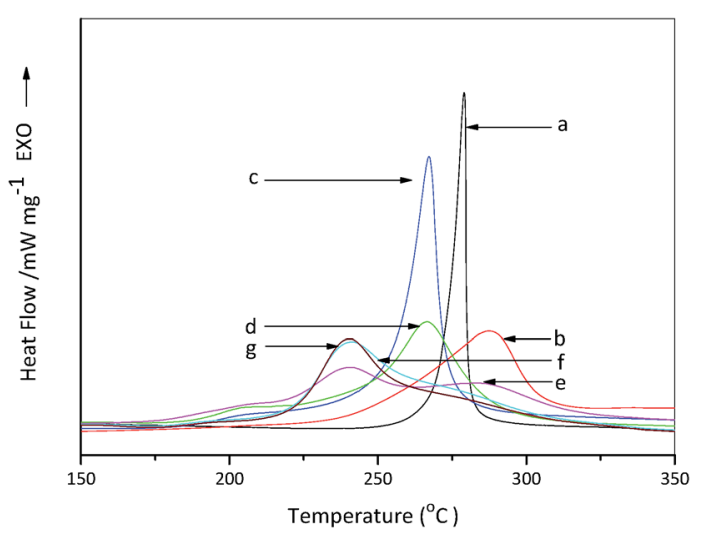

Fig. 8 DSC curves of PAN, P(AN-MA-AA) and P(AN-Co-MLA) copolymers heated at $10^{\circ} \mathrm{C} \mathrm{min}{ }^{-1}$. (a) PAN, (b) P(AN-AA-MA), (c) MLA/AN = 0.018 (wt/wt), (d) MLA/AN = 0.036 (wt/wt), (e) $\mathrm{MLA} / \mathrm{AN}=$ 0.055 (wt/wt), (f) $M L A / A N=0.074$ (wt/wt), (g) MLA/AN =0.093 (wt/wt). 
Table 5 Parameters for DSC curves of PAN, P(AN-AA-MA) and P(AN-CO-MLA) copolymers measured under $\mathrm{N}_{2}$ atmosphere

\begin{tabular}{|c|c|c|c|c|c|c|c|c|}
\hline $\begin{array}{l}\text { MLA/AN in polymers } \\
\text { (wt/wt) }\end{array}$ & $T_{\mathrm{i}}\left({ }^{\circ} \mathrm{C}\right)$ & $T_{\mathrm{p} 1}\left({ }^{\circ} \mathrm{C}\right)$ & $T_{\mathrm{p} 2}\left({ }^{\circ} \mathrm{C}\right)$ & $T_{\mathrm{p} 3}\left({ }^{\circ} \mathrm{C}\right)$ & $T_{\mathrm{f}}\left({ }^{\circ} \mathrm{C}\right)$ & $\Delta T\left({ }^{\circ} \mathrm{C}\right)$ & $\Delta H\left(\mathrm{~J} \mathrm{~g}^{-1}\right)$ & $\begin{array}{l}\Delta H / \Delta T \\
\left(\mathrm{~J} \mathrm{~g}^{-1}{ }^{\circ} \mathrm{C}^{-1}\right)\end{array}$ \\
\hline PAN & 244.16 & - & - & 278.99 & 303.11 & 58.95 & 2004.67 & 34.01 \\
\hline 0.018 & 178.39 & 208.58 & - & 267.25 & 305.94 & 127.58 & 2265.44 & 17.76 \\
\hline 0.036 & 176.49 & 208.13 & - & 266.52 & 319.53 & 143.04 & 2324.56 & 16.25 \\
\hline 0.055 & 175.11 & 207.68 & 241.59 & 283.48 & 323.22 & 148.11 & 2226.63 & 15.03 \\
\hline
\end{tabular}

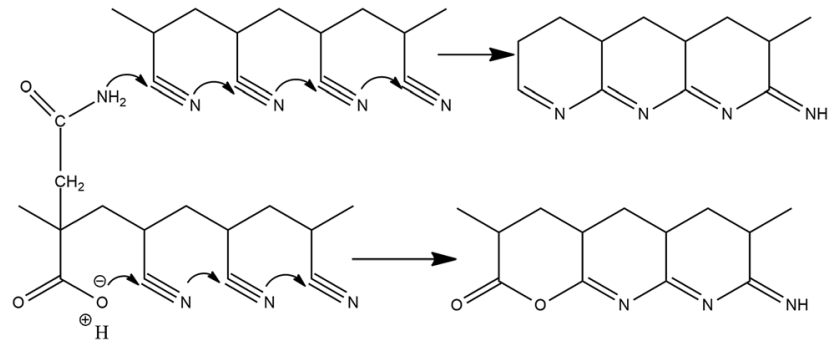

Fig. 9 Cyclization reactions initiated by MLA through ionic mechanism.

comonomer can make nucleophilic attack on the carbon atom of an adjacent nitrile group and then induce molecules to cyclize. There are three exothermic peaks in DSC curves $c, d, e, f$ and $g$ when the MLA/AN in P(AN-co-MLA) is $\geq 0.055$ (wt/wt). The lowest one is the cyclization initiated by carboxyl oxygen attack, the higher on is the cyclization initiated by amide nitrogen attack, the highest one is the cyclization initiated by free radical. These three cyclization reactions are competitive reactions. When the MLA/AN is $\leq 0.036$, the cyclization initiated by free radical are in the leading position. ${ }^{16}$ As the content of MLA increases, the cyclization initiated by amide nitrogen attack dominate the DSC curves.

As shown in Table 5, the cyclization temperatures of the $\mathrm{P}(\mathrm{AN}$ co-MLA) is ca. $175^{\circ} \mathrm{C}$ approximate $70^{\circ} \mathrm{C}$ and $25^{\circ} \mathrm{C}$ lower than that of the PAN homopolymer and $\mathrm{P}(\mathrm{AN}-\mathrm{MA}-\mathrm{AA})$ respectively, confirming the cyclization reactions in $\mathrm{P}(\mathrm{AN}-\mathrm{co}-\mathrm{MLA})$ are much easier to be initiated than in PAN and P(AN-MA-AA). And the $\Delta H$ of $\mathrm{P}$ (AN-co-MLA) copolymers improved by $10 \%$ or more compared with PAN and $\mathrm{P}(\mathrm{AN}-\mathrm{MA}-\mathrm{AA})$, suggesting more cyclization reactions occur in $\mathrm{P}(\mathrm{AN}-\mathrm{MA}-\mathrm{AA})$. It is beneficial to preparation of high performance carbon fiber. Obviously, MLA, which catalyzes the cyclization of nitrile groups through ionic mechanism, can improve significantly stabilization of $\mathrm{P}(\mathrm{AN}-\mathrm{co}-\mathrm{MLA})$. In addition, $\Delta H / \Delta T$ of $\mathrm{P}\left(\mathrm{AN}-\mathrm{co}\right.$-MLA) reduces from $34.01 \mathrm{~J} \mathrm{~g}^{-1}{ }^{\circ} \mathrm{C}^{-1}$ to less than $17.67 \mathrm{~J} \mathrm{~g}^{-1}{ }^{\circ} \mathrm{C}^{-1}$, indicating the comonomer MLA can relax exotherm during the stabilization and avoid the centralized heat release effectively.

\subsection{Evaluation of activation energy $\left(E_{\mathrm{a}}\right)$ of cyclization reactions}

Fig. 10 shows DSC curves of PAN, P(AN-MA-AA) with feed ratio of AN/MA/AA $=98 / 2 / 2(w t / w t / w t)$ and $\mathrm{P}(\mathrm{AN}-$ co-MLA) with MLA/AN
$=0.055$ (wt/wt) heated at different rates $(5,10,15,20$, $30{ }^{\circ} \mathrm{C} \min ^{-1}$ ) from $50{ }^{\circ} \mathrm{C}$ to $350{ }^{\circ} \mathrm{C}$ in $\mathrm{N}_{2}$ atmosphere (40 $\mathrm{mL} \mathrm{min}^{-1}$ ). As the heating rate increases, the whole exothermic peaks become stronger and shift to high temperatures (Table 6). The apparent activation energy $\left(E_{\mathrm{a}}\right)$ of the cyclization reactions was calculated by Kissinger ${ }^{40}$ and Ozawa methods. ${ }^{41}$ These two methods can be used to quantify $E_{\text {a }}$ without any prior knowledge of reaction mechanism but just requiring a series of DSC curves heated at different rates. ${ }^{42}$ The peak temperature $\left(T_{\mathrm{m}}\right)$, used by Kissinger and Ozawa methods to evaluate $E_{\mathrm{a}}$, are summarized in Table 7 . The $T_{\mathrm{m}}$ of DSC shows a regular increase with the increase of heating rate $(\varphi)$.

The equation used by Kissinger's method are as follows: ${ }^{39}$

$$
-\frac{E_{\mathrm{a}}}{R}=\frac{\mathrm{d}\left[\ln \left(\varphi / T_{\mathrm{m}}{ }^{2}\right)\right]}{\mathrm{d}\left(1 / T_{\mathrm{m}}\right)}
$$

$E_{\mathrm{a}}$ was calculated from the slope of the linear plot of $\ln \varphi / T_{\mathrm{m}}{ }^{2}$ versus $1000 / T_{\mathrm{m}}$ as shown in Fig. 11(1).

Ozawa's method uses the following equation: ${ }^{40}$

$$
-\frac{E_{\mathrm{a}}}{R}=2.15 \frac{\mathrm{d}(\log \varphi)}{\mathrm{d}\left(1 / T_{\mathrm{m}}\right)}
$$

$E_{\mathrm{a}}$ was calculated from the slope of the linear plot of $\log \varphi$ versus $1000 / T_{\mathrm{m}}$ as shown in Fig. 11(2).

Table 7 shows the $E_{\mathrm{a}}$ of cyclization reactions of PAN, P(ANMA-AA) with AN/MA/AA = 98/2/2 (wt/wt/wt) and P(AN-co-MLA) copolymers with MLA/AN $=0.018,0.036,0.055,0.074,0.093$ (wt/wt). The $E_{\mathrm{a}}$ determined by Kissinger method agrees well with that obtained by Ozawa method for all polymers. The $E_{\text {a }}$ values of cyclization reactions for PAN homopolymer and $\mathrm{P}(\mathrm{AN}-$ MA-AA) copolymer are about $168 \mathrm{~kJ} \mathrm{~mol}^{-1}$ and $140 \mathrm{~kJ} \mathrm{~mol}^{-1}$, respectively. While the $E_{\mathrm{a}}$ of $\mathrm{P}(\mathrm{AN}-c o-\mathrm{MLA})$ copolymer has been splitted into two or three parts. As for $\mathrm{P}(\mathrm{AN}-\mathrm{co}-\mathrm{MLA})$ with MLA/ $\mathrm{AN} \geq 0.055$, the first and second parts, which are assigned to the ionic cyclization reactions initiated by carboxyl oxygen and amide nitrogen respectively. Which are calculated from the two lower exothermic peaks and the $E_{\mathrm{a}}$ are about $112 \mathrm{~kJ} \mathrm{~mol}^{-1}$ and $109 \mathrm{~kJ} \mathrm{~mol}^{-1}$. Obviously, the $E_{\mathrm{a}}$ of P(AN-co-MLA) copolymer has been reduced significantly compared with that of PAN homopolymer and $\mathrm{P}(\mathrm{AN}-\mathrm{MA}-\mathrm{AA})$ copolymer, manifesting the cyclization is easier to be initiated in $\mathrm{P}(\mathrm{AN}-\mathrm{co}-\mathrm{MLA})$ than in PAN and $\mathrm{P}(\mathrm{AN}-\mathrm{MA}-\mathrm{AA})$. The third part calculated from the highest exothermic peak is about $168 \mathrm{~kJ} \mathrm{~mol}^{-1}$, which is assigned to the radical cyclization reactions and closed to that of PAN 

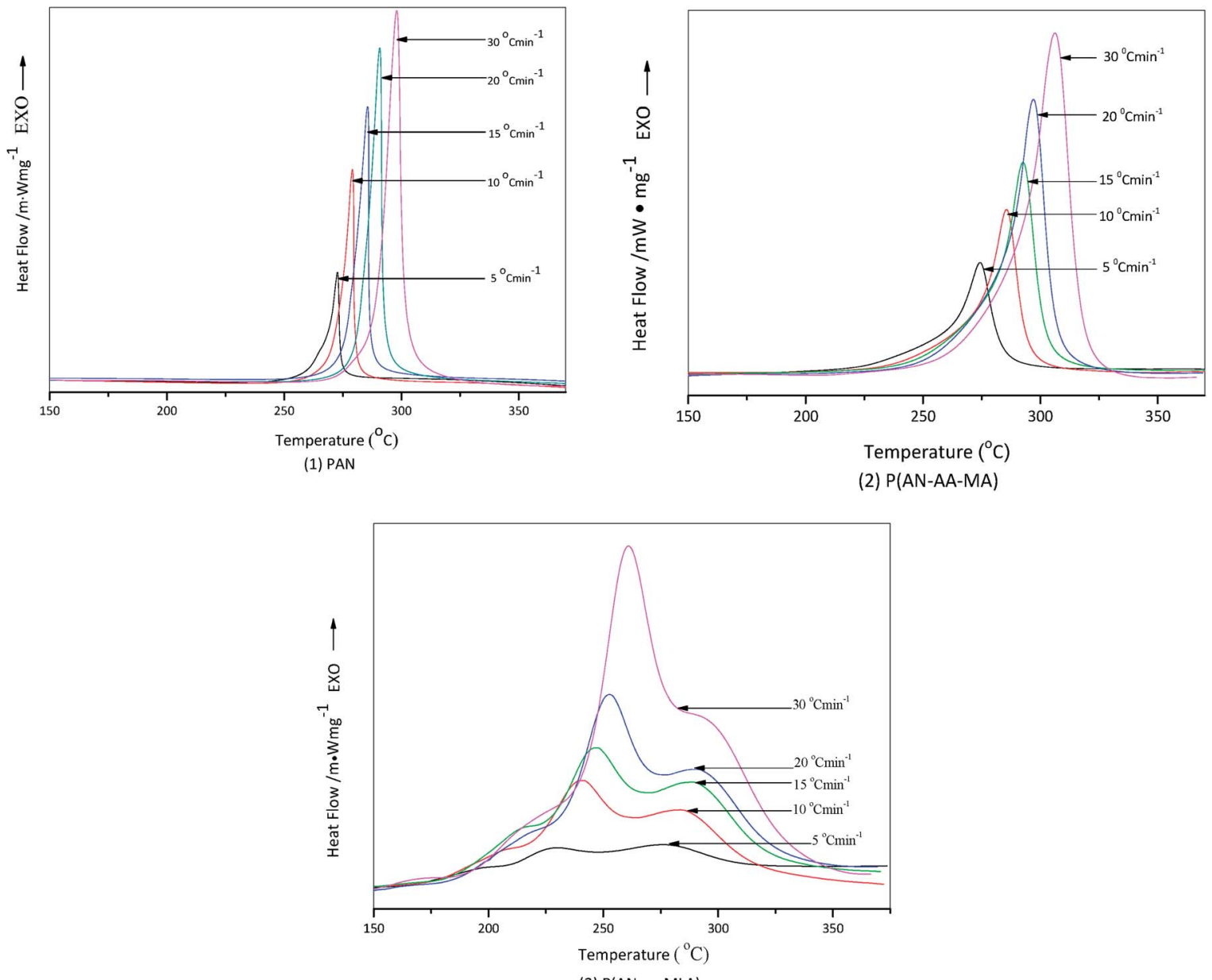

Fig. 10 DSC curves of (1) PAN, (2) P(AN-MA-AA) with feed ratio ofAN/MA/AA = 98/2/2 and (3) P(AN-CO-MLA) with MLA/AN =0.055 heated at different rate.

Table 6 DSC peak maxima for PAN polymers heated at different rates

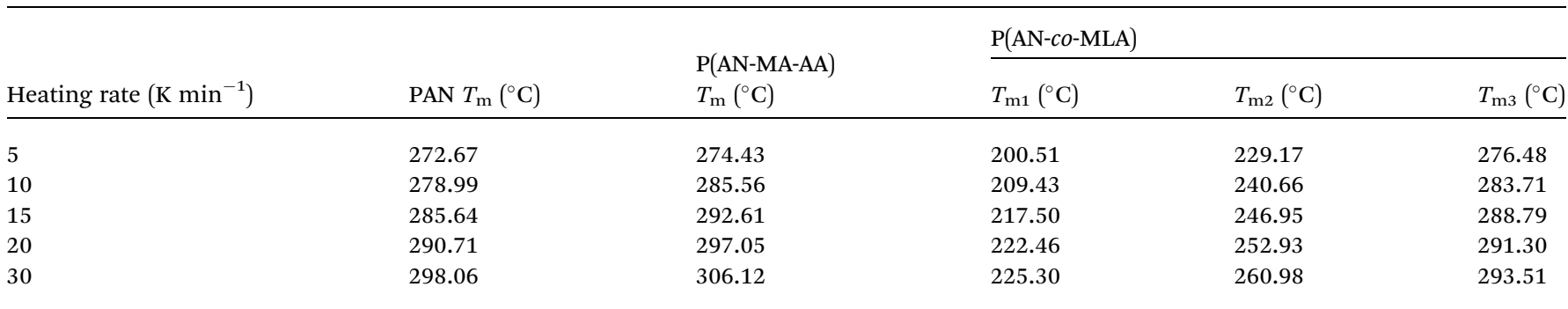

Table $7 \quad E_{a}$ determined by Kissinger and Ozawa methods

\begin{tabular}{|c|c|c|c|c|c|c|c|c|}
\hline Method & Peak & PAN & P(AN-MA-AA) & $\begin{array}{l}\text { MLA/AN in } \\
\text { polymer }=0.018\end{array}$ & $\begin{array}{l}\text { MLA/AN in } \\
\text { polymer }=0.036\end{array}$ & $\begin{array}{l}\text { MLA/AN in } \\
\text { polymer }=0.055\end{array}$ & $\begin{array}{l}\text { MLA/AN in } \\
\text { polymer }=0.074\end{array}$ & $\begin{array}{l}\text { MLA/AN in } \\
\text { polymer }=0.093\end{array}$ \\
\hline \multirow[t]{2}{*}{ Kissinger } & Peak 1 & 168.36 & 141.49 & 115.47 & 114.79 & 123.80 & 102.36 & 101.19 \\
\hline & Peak 3 & & & 168.55 & 186.13 & 227.47 & 164.53 & 156.54 \\
\hline \multirow[t]{2}{*}{ Ozawa } & Peak 1 & 165.89 & 140.86 & 115.40 & 114.74 & 123.16 & 102.93 & 101.85 \\
\hline & Peak 2 & & & - & - & 117.98 & 106.68 & 107.52 \\
\hline
\end{tabular}




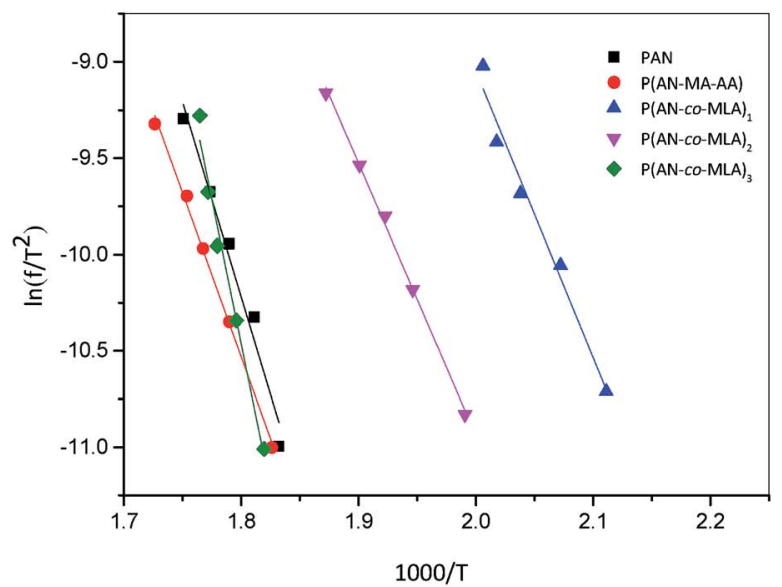

(1) Kissinger method

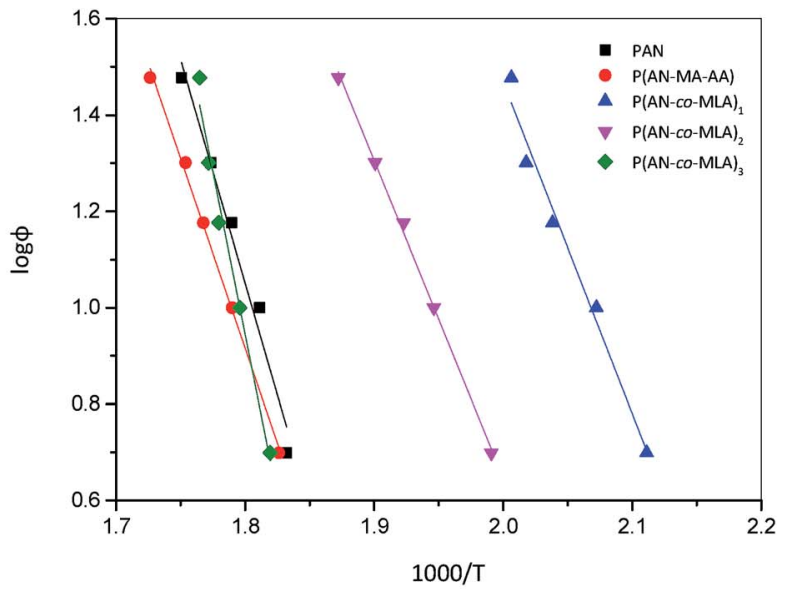

(2) Ozawa method

Fig. 11 Kissinger method (1) and Ozawa method (2) used to quantify $E_{a}$ of PAN, P(AN-MA-AA) and P(AN-CO-MLA) with MLA/AN =0.055.

homopolymer. The above results further confirm that the synthesized comonomer MLA can significantly promote the stabilization of $\mathrm{P}\left(\mathrm{AN}-c o\right.$-MLA) with lower $E_{\mathrm{a}}$.

\section{Conclusions}

The P(AN-co-MLA) copolymers with different compositions were synthesized successfully by solution polymerization using a novel bifunctional MLA as comonomer. Both the conversion and molecular weight of polymerization decreases with the increase of MLA content because of the large molecular volume of MLA. The amounts of comonomer in the feed should be controlled less than $3.0 \mathrm{wt} \%$ to get high molecular weight $\mathrm{P}$ (AN-co-MLA) as carbon fiber precursor. Due to ionic initiation of MLA, the cyclization of $\mathrm{P}(\mathrm{AN}-\mathrm{co}$-MLA) was significantly improved, such as lower initiation temperature, broadened exothermic peak, larger extent of stabilization and lower cyclization $E_{\mathrm{a}}$, which is beneficial to preparation of high performance carbon fiber.

\section{Conflicts of interest}

There are no conflicts to declare.

\section{Acknowledgements}

Financial support of this work from National Natural Science Foundation of China (No. 51503086), Natural Science Foundation of Jiangsu Province (No. BK20140159), State Key Laboratory for Modification of Chemical Fibers and Polymer (17M1060121), Key Laboratory of Science \& Technology of EcoTextile (Donghua University/Jiangnan University, No. 273-100001097), Ministry of Education, China and the Fundamental Research Funds for the Central Universities (No. 17D110620). Young Teachers of Donghua University (No. 106-07-0053106) was gratefully acknowledged.

\section{Notes and references}

1 H. G. Chae, B. A. Newcomb, P. V. Gulgunje, Y. D. Liu, K. K. Gupta, M. G. Kamath, K. M. Lyons, S. Ghoshal, C. Pramanik, L. Giannuzzi, K. Sahin, I. Chasiotis and S. Kumar, Carbon, 2015, 93, 81-87.

2 E. Frank, L. M. Steudle, D. Ingildeev, J. M. Sporl and M. R. Buchmeiser, Angew. Chem., Int. Ed., 2014, 53, 52625298.

3 E. Frank, F. Hermanutz and M. R. Buchmeiser, Macromol. Mater. Eng., 2012, 297, 493-501.

4 T. A. Khan, A. Gupta, S. S. Jamari, R. Jose, M. Nasir and A. Kumar, BioResources, 2013, 8, 4171-4184.

5 S. W. Lee, H. Y. Lee, S. Y. Jang, S. Jo, H. S. Lee, W. H. Choe and S. Lee, Carbon, 2013, 55, 361-365.

6 Z. Bashir, Carbon, 1991, 29, 1081-1090.

7 M. X. Ji, C. G. Wang, Y. J. Bai, M. J. Yu and Y. X. Wang, Polym. Bull., 2007, 59, 527-536.

8 X. Li, X. F. Ji and C. J. He, RSC Adv., 2015, 5, 81399-81406.

9 Y. Yang, X. Li, L. D. Shen, X. F. Wang and B. S. Hsiao, Ind. Eng. Chem. Res., 2017, 56, 3077-3090.

10 M. Buback and L. Wittkowski, Macromol. Chem. Phys., 2000, 201, 419-426.

11 Z. Y. Fu, B. J. Liu and H. X. Zhang, J. Appl. Polym. Sci., 2017, 134, 7.

12 R. Devasia, C. P. R. Nair and K. N. Ninan, Eur. Polym. J., 2002, 38, 2003-2010.

13 E. Ismar and A. S. Sarac, Polym. Adv. Technol., 2016, 27, 13831388.

14 A. Shokuhfar, A. Sedghi and R. E. Farsani, Mater. Sci. Technol., 2006, 22, 1235-1239.

15 Z. Y. Fu, B. J. Liu, Y. J. Deng, J. Y. Ma, C. L. Cao, J. Wang, Y. H. Ao and H. X. Zhang, J. Appl. Polym. Sci., 2016, 133, 10.

16 R. Devasia, C. P. Reghunadhan, N. P. Sivadasan, B. K. Katherine and K. N. Ninan, J. Appl. Polym. Sci., 2003, 88, 915-920. 
17 Z. P. Zeng, Z. C. Shao, R. Xiao and Y. G. Lu, Chin. J. Polym. Sci., 2017, 35, 1020-1034.

18 N. Yusof and A. F. Ismail, Polym. Eng. Sci., 2012, 52, 360-366. 19 P. Rangarajan, J. Yang, V. Bhanu, D. Godshall, J. McGrath,

G. Wilkes and D. Baird, J. Appl. Polym. Sci., 2002, 85, 69-83.

20 H. Kakida and K. Tashiro, Polym. J., 1997, 29, 557-562.

21 D. X. He, C. G. Wang, Y. J. Bai and B. Zhu, J. Mater. Sci. Technol., 2005, 21, 376-380.

22 M. S. A. Rahaman, A. F. Ismail and A. Mustafa, Polym. Degrad. Stab., 2007, 92, 1421-1432.

23 J. Kaur, K. Millington and S. Smith, J. Appl. Polym. Sci., 2016, 133, 14.

24 P. Bajaj, T. V. Sreekumar and K. Sen, Polymer, 2001, 42, 17071718.

25 O. K. Park, S. Lee, H. I. Joh, J. K. Kim, P. H. Kang, J. H. Lee and B. C. Ku, Polymer, 2012, 53, 2168-2174.

26 Y. Q. Zhao, C. G. Wang, Y. J. Bai, G. W. Chen, M. Jing and B. Zhu, J. Colloid Interface Sci., 2008, 329, 48-53.

27 W. X. Zhang, J. Liu and G. Wu, Carbon, 2003, 41, 2805-2812. 28 Y. Q. Zhao, C. G. Wang, M. J. Yu, C. S. Cui, Q. F. Wang and B. Zhu, J. Polym. Res., 2009, 16, 437-442.

29 Y. J. Xu, M. Tian and Z. P. Yao, Abstr. Pap. Am. Chem Soc. Natl. Meet., 2014, 247, 1.

30 D. Salary, S. Alizadeh, B. Massoumi and A. Entezami, J. Polym. Mater., 2002, 19, 335-342.
31 G. X. Zhao, B. J. Chen and S. A. Qian, J. Anal. Appl. Pyrolysis, 1992, 23, 87-97.

32 J. Zhao, J. H. Zhang, T. Zhou, X. F. Liu, Q. Yuan and A. M. Zhang, RSC Adv., 2016, 6, 4397-4409.

33 I. Shimada, T. Takahagi, M. Fukuhara, K. Morita and A. Ishitani, J. Polym. Sci., Polym. Chem. Ed., 1986, 24, 19891995.

34 D. H. Li, C. X. Lu, G. P. Wu, J. J. Hao, Y. Yang, Z. H. Feng, X. T. Li, F. An and B. P. Zhang, J. Appl. Crystallogr., 2014, 47, 1809-1818.

35 H. Rennhofer, D. Loidl, S. Puchegger and H. Peterlik, Carbon, 2010, 48, 964-971.

36 X. M. Ren, Y. S. Wang, T. He and Z. C. Xia, J. Wuhan Univ. Technol., Mater. Sci. Ed., 2014, 29, 224-228.

37 M. J. Yu, Y. J. Bai, C. G. Wang, Y. Xu and P. Z. Guo, Mater. Lett., 2007, 61, 2292-2294.

38 A. Q. Ju, S. Y. Guang and H. Y. Xu, Carbon, 2013, 54, 323-335. 39 Y. Furushima, M. Nakada, H. Takahashi and K. Ishikiriyama, Polymer, 2014, 55, 3075-3081.

40 H. E. Kissinger, Anal. Chem., 1957, 29, 1702-1706.

41 T. Ozawa, Bull. Chem. Soc. Jpn., 1965, 38, 1881-1886.

42 S. P. Rwei, T. F. Way and Y. S. Hsu, Polym. Degrad. Stab., 2013, 98, 2072-2080. 